\title{
Genotyping Diversity of \\ Pseudomonas aeruginosa Isolates, Isolated from Baquba City
}

\author{
Aghadeer Sarmad Najeeb ${ }^{1}$, Hadi Rahman Rasheed Al-Taai ${ }^{2}$

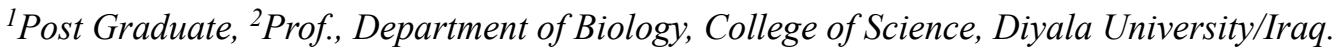

\begin{abstract}
This research aims to assess the similarities and variances between MDR Pseudomonas aeruginosa clinical isolates from different infections using MLST molecular typing technique in Baquba city. One hundredeighty clinical samples were collected from urinary tract, wounds and burns infections, included (110) urine, (50) wounds and (20) burns. Twenty isolates (11.11\%) of Pseudomonas aeruginosa were diagnosed based on microscopic, morphological, biochemical tests and confirmed by VITEK-2 system. Antibiotic susceptibility test for the twenty isolates was performed against six antibiotics using disk diffusion method, the results showed (100\%) resistance for Cephalothin, Ceftazdim (60\%), Colistin (35\%), Amikacin (25\%), Ciprofloxacin (20\%), while (0\%) resistance for Imipenem. The results also showed that $16(80 \%)$ of isolates were produced extended spectrum beta-lactamase (ES $\beta \mathrm{L})$ and did not show their production for Metallobeta-lactamase (M $\beta L$ s). Biofilm was detected by Micro-Titer Plate method and the result showed that all the isolates $(100 \%)$ were biofilm producers. Multi-locus sequence typing (MLST) was used because broadness and ease of access of MLST database. Seven housekeeping genes $(a c s \mathrm{~A}, \operatorname{aro\mathrm {E}}, g u a \mathrm{~A}, m u t \mathrm{~L}, n u o \mathrm{D}, p p s \mathrm{~A}$, and $t r p \mathrm{E}$ ) were sequenced and the results were compared with MLST database and allele profile for each isolate was used to determine sequence types (STs).New Iraqi bacterial strain has been identified and recorded in database of MLST (PubMLST) under the name (AS-85U).
\end{abstract}

Keywords: Pseudomonas aeruginosa, Biofilm, MLST.

\section{Introduction}

Pseudomonas aeruginosa is known as an opportunistic pathogen with a range of virulence factors in humans including biofilms formation, toxins that causing broadtissue damage hence, accessto bloodstream and spreading to body tissue, as a role of colonization, invasion and persistence in human host ${ }^{(1)}$. $P$. aerugenosa represents a phenomenon of resistance to many antibiotics creatinghard to treatinfections. This bacteria has natural resistance such as chromosomal expression, changing outer membrane permeability ${ }^{(2)}$,

\footnotetext{
Corresponding Author: Aghadeer Sarmad Najeeb Post Graduate, Department of Biology, College of Science, Diyala University/Iraq e-mail: alshblyahmed4@gmail.com
}

and have many groups of efflux pumps ${ }^{(3)}$. In addition to production of many enzymes able to antibiotics lysis especially $\beta$-lactams such as Metallo $\beta$-Lactamases (M $\beta$ Ls), Extended spectrum $\beta$-Lactamases (ES $\beta$ Ls) and Ampler molecular class (AMPC) ${ }^{(4)}$.

Due to its ability to develop multidrug resistance (MDR), extensively drug resistant (XDR), and pandrugresistant (PDR) $P$. aeruginosa has gradually become a prevalent in nosocomial infections ${ }^{(5)}$. The plasticity and complexity of the large $P$. aeruginosa genome (6.3Mbp) reveals the evolutionary adaptations conversed to this species $^{(6)}$. It comprises conserved core genome with strain definiteregions that permit strains to gain or shed genomic fragments for improvement of survival traits in a wide range of environment ${ }^{(7)}$.

In order to distinguish between the isolates and clonal groups of $P$. aeruginosa, some molecular typing schemes have been described ${ }^{(8)}$. Multilocus sequence 
typing (MLST) is an alternative method for molecular typing which is a global and accuratestrain-typing system that concentrates entirely on conserved housekeeping genes and the combination of each allele ${ }^{(9)}$. This is aim to define the sequence type (ST) for each isolate and provide information in the relatedness of bacterial isolates at the core genome level. MLST scheme has been first advanced for $P$. aeruginosa by Curran et al. ${ }^{(10)}$ and had the most analytical value (100\%) in labeling strains as unique $^{(11)}$. The standardization of MLST has given increase to databases which allow comparative analysis of allele sequences and documentation of distinctive sequence types ${ }^{(12)}$.

\section{Materials and Method}

Isolates activation: All the twenty $P$. aeruginosa's isolates from different infection sources have been activated, and diagnosed depending on morphological, biochemical tests, and confirmed by VITEK-2 system.

Antimicrobial susceptibility testing: Antimicrobial susceptibility test was performed using (Kirby-Bauer standard disk diffusion method) on MuellerHinton agar plates against six antibiotics according to Franklin et al. ${ }^{(13)}$ based on CLSI ${ }^{(14)}$.

\section{Biofilm detection}

The Micro Titer Plate method (MTP) was used as following:

$P$. aeruginosa isolates were cultured on nutrient broth for $18-24 \mathrm{hr}$ at $37^{\circ} \mathrm{C}$ aerobically. After incubation 2-4 colonies were picked up and cultured in nutrient broth until the turbidity equivalent to $0.5 \mathrm{McF}$ arland $\left(1.5 \times 10^{8} \mathrm{CFU} / \mathrm{ml}\right) .200 \mu \mathrm{L}$ of the bacterial suspensions were transferred into polystyrene micro-titer plates containing 96 flat-bottom wells and a broth without bacterial inoculum was used as the negative control. The plate was sealed and incubated for $24 \mathrm{hr}$. The bacterial suspensions then removed, and each well was washed three times with sterile saline solution $(0.9 \% \mathrm{NaCl})$. Next, the cells stuck on the walls were fixed with 200 $\mu \mathrm{L}$ of methanol for 10-15 minutes. The methanol was removed, the plates were left at room temperature to dry and they were stained with $200 \mu \mathrm{L}$ of crystal violet $0.5 \%$ for 10-15 minutes. The plates then washed with distilled water 2-3 times and dried at room temperature ${ }^{(15)}$. The absorbency were taken in an ELISA reader at wavelength of $630 \mathrm{~nm}$, according to Tang et $a^{(16)}$. The value of the optical densities for each isolate (ODi) was obtained by averaging the three wells, and this value was compared to the optical density of the negative control (ODc). The isolates were classified into four categories, according to the mean optical densities (ODi) in relation to the ODc results.

If ODi $\leq$ ODc; considered non-adherent, $\mathrm{ODc} \leq \mathrm{ODi} \leq 2 * \mathrm{ODc}$; considered moderately adherent and if $2 * \mathrm{OD} c \leq \mathrm{ODi}$ which considered strongly adherent.

The formation degree of biofilm production = Optical density of tested isolates - Optical density of control.

Production of ES $\beta$ Ls detection: ESBL production in $P$. aeruginosa was identified by the double disk synergy test (DDST) as described by Jarlieret $a l^{(17)}$.

Mueller-Hinton agar plates were streaked with inoculum (equivalent to $0.5 \mathrm{McF}$ arland) using a sterile cotton swab. An Augmentin (20 $\mu \mathrm{g}$ amoxicillin and $10 \mu \mathrm{g}$ of clavulanic acid) disk placed in the center of the plate and, ceftazidime $(30 \mu \mathrm{g})$, aztreonam $(30 \mu \mathrm{g})$ ciprofloxacin $(30 \mu \mathrm{g})$ were placed $15 \mathrm{~mm}$ separatelycenter to center on the plates with a sterile forceps ${ }^{(18)}$. The plates were then incubated for $18-24 \mathrm{hr}$ at $35-37^{\circ} \mathrm{C}$. An enhanced inhibitionzones from $5 \mathrm{~mm}$ or more in the presence of Augmentin is suggested as positive result for the production of ESBL enzyme ${ }^{(19)}$.

\section{Molecular typing}

Selection of loci for MLST: The seven housekeeping genes for P.aeruginosa were chosen according to MLST scheme firstly designed by Curran et $\mathrm{al}^{(10)}$ based on their biological function (mismatch repair, DNA replication and amino acid biosynthesis), size, location (a minimum of $6 \mathrm{kbp}$ upstream or downstream from known virulence factors, lysogenic phage, or insertion sequence elements), and suitability for nested primer design and sequence diversity ${ }^{(12)}$.

DNA extraction: Genomic DNA was extracted according to the protocol of ABIOpureTM Total DNAExtraction kit/USA.

PCR primer for MLST: MLST was performed on four selected isolates out of twenty in order to investigate which sequence types of P.aeruginosa were present in Baquba city. The PCR primers described by Curran et $\mathrm{al}^{(10)}$ were used and prepared according to the manufacturer's instructions installed in the working method of equipped company (Macrogen, Korea) to 
become a primer in the final concentration $100 \mathrm{pmol} / \mu \mathrm{l}$. Primers for the housekeeping genes used in the MLST scheme were mentioned in table (1).

Amplification of loci: All extracted DNA from the four isolates went through PCR procedure in order to target the seven genes under study. Each reaction components contained $2 \mathrm{ng} / \mu \mathrm{l}$ chromosomal DNA, $1 \mu \mathrm{l}$ forward primer $(10 \mu \mathrm{M}), 1 \mu 1$ reverse primer $(10 \mu \mathrm{M})$, $12.5 \mu 1$ master mix $(2 \mathrm{x})$ and $8.5 \mu 1$ nuclease free $\mathrm{H} 2 \mathrm{O}$. The reaction conditions were: initial denaturation at $95^{\circ} \mathrm{C}$ for $5 \mathrm{~min}$, denaturation at $95^{\circ} \mathrm{C}$ for $30 \mathrm{sec}$, primer annealing at $55^{\circ} \mathrm{C}$ for $30 \mathrm{sec}$, extension at $72^{\circ} \mathrm{C}$ for $1 \mathrm{~min}$ and the final extension at $72^{\circ} \mathrm{C}$ for $7 \mathrm{~min}$. the amplification product was purified before sequencing process.

Table (1): Sequences and primers sizes for the seven housekeeping genes

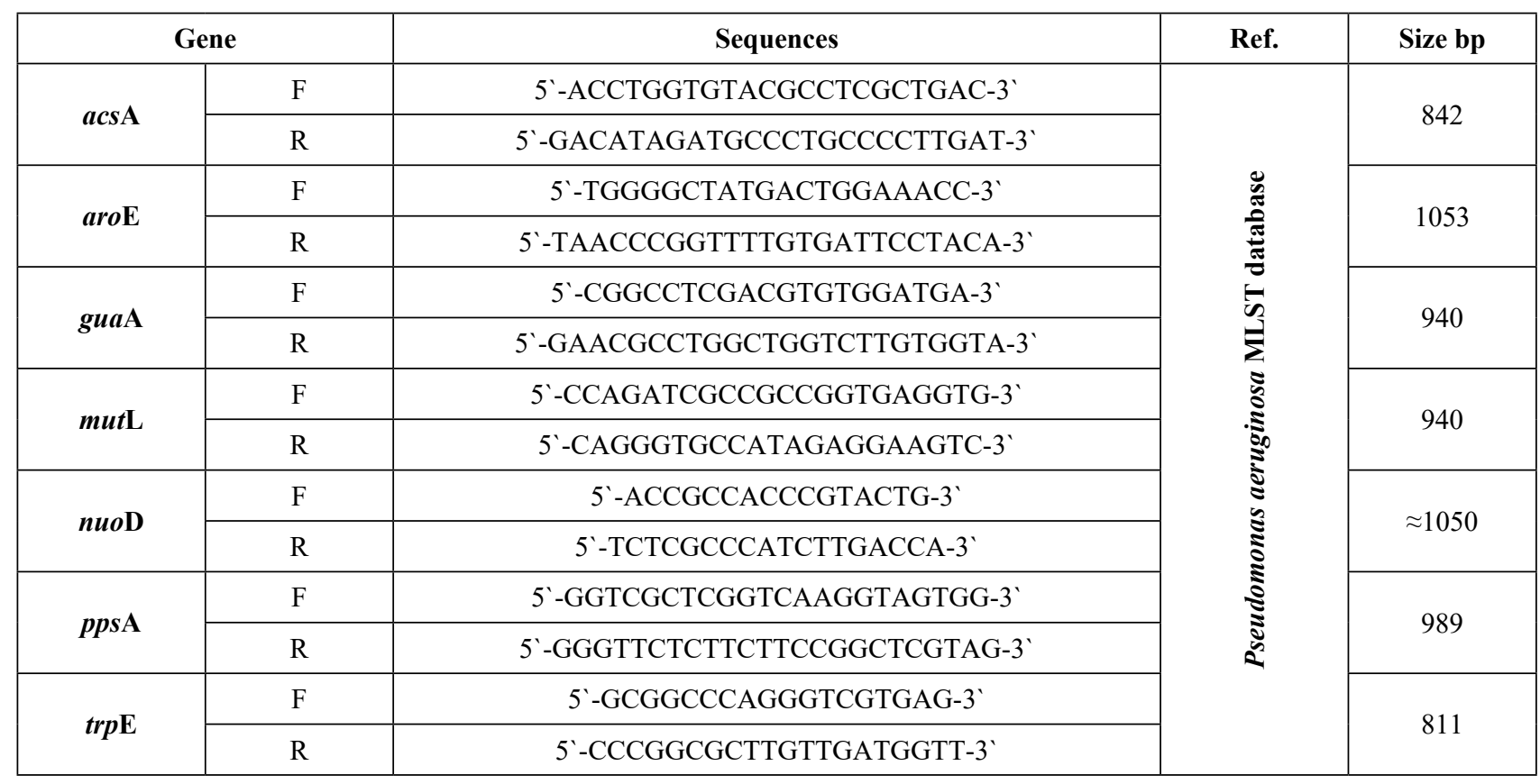

Sequencing and blasting;: Sequencing was performed for all 7 genes of the 4 isolates. PCR product were sent for Sanger sequencing using ABI3730XL, automated DNA sequencers, by Macrogen Corporation - Korea. The results were received by email then analyzed using genius software. To get an allelic profile, the results were blasted in the Pseudomonas aeruginosa MLST Database (http://pubmlst.org/paeruginosa), and then the database was used to search for the STs defined by those specific allelic profiles. The sequences were confirmed through individual BLAST searches to determine their correspondence with previously sequenced $P$. aeruginosa genomes. Then the full aligned sequences were saved in FASTA format.

Allele and sequence type assignment: Based upon the allele numbering system in the $P$. aeruginosa MLST database, an allele number was appointedfor every gene in each isolate. Alleles that differed by even a one base pair from those present in the database were denominated as "new." Each distinct combination of seven numbers (denotingthe seven alleles) was assigned a number denoting its sequence type (ST) according to the MLST database. Combinations not present in the database were considered "new" STs.

\section{Results}

Antibiotics sensitivity test: Isolates under study showed $100 \%$ resistance for Cephalothin $(\mathrm{KF})$, this result agree with Hameed ${ }^{20)}$ which was $100 \%$ resistance. Ceftazidime (CAZ) showed 60\% resistance which is similar to Kaur and Singh (21) finding. The resistance to Amikacin (AK) and Ciprofloxacin (CP) was $25 \%$ and $20 \%$ respectively, this result agree with Fattma et al ${ }^{(22)} 25 \%$ and $35 \%$ respectively while Colistin showed $35 \%$ resistance. Finally, the resistance to Impinem was $0 \%(100 \%$ sensitive) and this result is consistence with Hameed ${ }^{(20)}$ finding which was $0 \%$, table (3). 
Table (2): Number and percentages for sensitivity and resistance isolates

\begin{tabular}{|c|c|c|c|}
\hline \multirow{2}{*}{ Antibiotics } & \multicolumn{3}{|c|}{ Isolates number (\%) } \\
\cline { 2 - 4 } & Sensitive & Intermediate & Resistance \\
\hline IMP & $20(100)$ & $0(0)$ & $0(0)$ \\
\hline Co & $13(65)$ & $0(0)$ & $7(35)$ \\
\hline CAZ & $8(40)$ & $0(0)$ & $5(25)$ \\
\hline AK & $15(75)$ & $0(0)$ & $20(100)$ \\
\hline KF & $0(0)$ & $0(0)$ & $4(20)$ \\
\hline CP & $14(70)$ & $2(10)$ & \\
\hline
\end{tabular}

Biofilm production: The results showed that all the isolates included in the study had the properties of biofilms formation and the absorbency value was ranged from $(0.186-0.21)$ and $25 \%$ of isolates were strongly biofilm forming this agree with Hameed $^{(20)}$ finding which was $25 \%, 75 \%$ for moderately biofilm forming.

\section{Extended Spectrum $\beta$ - Lactamase Enzyme} (ESBLs): The results showed that $16(80 \%)$ of isolates under study were ES $\beta$ Ls producer and 4 (20\%) nonproducing. This result is nearly to $\mathrm{Hyford}^{(23)}$ result which was $88 \%$ of clinical isolates were producing these enzymes.
Multi locus Sequence Typing (MLST) and allelic profile: Allele profiles and STs can be found at (http:// pubmlst.org/paeruginosa). By comparing the sequence and combination of genes the clonal relationship between isolates can be assessed ${ }^{(10)}$. It has been reported that isolates with the same sequence types (ST) can be considered as members of the same clone, and $P$. aeruginosa isolates that share at least five of the seven numbers within their allelic profile were regarded as members of the same clonal complex ${ }^{(24)}$ table (3).

Table (3): MLST allelic profile and strain type for P.aeruginosa isolates

\begin{tabular}{|c|c|c|c|c|c|c|c|c|}
\hline \multirow{2}{*}{$\begin{array}{l}\text { Isolates } \\
\text { number }\end{array}$} & \multicolumn{7}{|c|}{ Allelic type } & \multirow{2}{*}{ STs } \\
\hline & $\operatorname{acs} \mathbf{A}$ & $\operatorname{aroE}$ & guaA & $m u t \mathrm{~L}$ & nuoD & ppsA & $\operatorname{trp} \mathbf{E}$ & \\
\hline 5 & 38 & 11 & 3 & 13 & 1 & 2 & 4 & 235 \\
\hline 7 & 11 & 20 & 1 & 65 & 4 & 4 & 273 & New \\
\hline 9 & 16 & 4 & 11 & 3 & 2 & 4 & 1 & 2547 \\
\hline 10 & 38 & 11 & 3 & 13 & 1 & 2 & 4 & 235 \\
\hline
\end{tabular}

*In MLST database any allele not contained within database was designated as "new"

Nucleotides Sequencing of MLST: In an effort to compare MLST genes heterogenicity, polymerase chain reaction products of seven genes for $P$. aeruginosa isolates were sent for determining the nucleotide sequence. Sequencing was determined by an automatic sequencer. DNA sequences were analyzed and similarity were accomplished among genes of local $P$. aeruginosa and standard strains with Basic Local Alignment Search Tool (BLAST) in National Center for Biotechnology Information (NCBI). A subsequent BLAST search showed a $99-100 \%$ match to P.aeruginosa genomes present in GenBank for acs A sequences of these isolates, which confirmed their identity as P.aeruginosa.

New bacterial strain identification: One bacterial isolate (P7) was identified as global new Iraqi strain for differences in some nucleotide position. This new strain AS-85U was published in the MLST database https:// pubmlst.org/paeruginosa/ 


\section{Conclusions}

Pseudomonas aeruginosa has several genetic elements that support their pathogenicity (virulence and antibiotics resistance) and the resistance of Pseudomonas aeruginosa to most antibiotics in the study indicating a correlation between multidrug resistance to antibiotics and the production of (ES $\beta$ Ls) enzymes and biofilm formation. Molecular techniquesprovidea sensitive and rapid analytical tools for identification, sequencing and increases the excellence of epidemiological investigations. The newly-developed MLST method for multi locus typing of P.aeruginosasuggests an accurate diagnosis of the bacteria and detection of the source of infections and treatment.

Ethical Clearance: The Research Ethical Committee at scientific research by ethical approval of both environmental and health and higher education and scientific research ministries in Iraq

Conflict of Interest: The authors declare that they have no conflict of interest.

Funding: Self-funding

\section{References}

1. Mahmoud BA,Zahran AW, Hindawi RG, Labib ZA and Galal R. Prevalence of multidrugresistant Pseudomonas aeruginosa in patients with nosocomial infections at a University Hospital in Egypt, with special reference to typing method. JVM.2013; 13. 1.

2. BreidensteinEBM, Fuente-Nunez $\mathrm{CI}$ and Hancock REW. Pseudomonas aeruginosa: all roads lead to resistance. International J. Antimicrobial Agents.2011; 19(8): 419-426.

3. Morita $\mathrm{Y}$, Tomida J and Kawamura Y. MexXY multidrug efflux system of Pseudomonas aeruginosa. Front Microbiol.2012; 3(408): 1-13.

4. Park AJ,Surette MD,KhursigaraC M. Antimicrobial targets localize to the extra cellular vesicle associated proteome of Pseudomonas aeruginosa grown in a biofilm. Antimicrob. Res. Chemother.2014; 5(464): 1-12.

5. Yali G, Jing C, Chunjiang L, Cheng Z, Xiaoqiang $\mathrm{L}$ and Yizhi $\mathrm{P}$. Comparison of pathogens and antibiotic resistance of burn patients in the burn ICU or in the common burn ward. Burns.2014: 402-407.
6. Cristina $\mathrm{N}$ and Eusébio L. Identification and Genotyping of Pseudomonas aeruginosa in Bronchiectasis. Thesis submitted to the Institute of Molecular Pathology and Immunologyof University of Porto.2013:1-83.

7. Mathee K, Narasimhan G, Valdes C, Qiu X, Matewish JM, Koehrsen M, Rokas A, Yandava CN, Engels R, Zeng E, Olavarietta R, Doud M, Smith RS, Montgomery P, White JR, Godfrey PA, Kodira C, Birren B, Galagan JE, Lory S.Dynamics of Pseudomonas aeruginosa genome evolution. Proc Natl Acad Sci U S A.2008; 105(8): 31003105 .

8. Inacio $\mathrm{H}$ S, Bomfim MR, França RO, Farias LM, Carvalho MA, Serufo JC, Santos SG.. Phenotypic and genotypic diversity of multidrugresistant Pseudomonas aeruginosa Isolates from bloodstream infections recovered in the Hospitals of Belo Horizonte, Brazil. Chemotherapy.2014; 60(1):54-62. PMID: 25402327.

9. Maiden MC, Bygraves JA, Feil E, Morelli G, Russell JE, Urwin R, Zhang Q, Zhou J, Zurth K, Caugant DA, Feavers IM, Achtman M, Spratt BG.Multilocus sequence typing: a portable approach to the identification of clones within populations of pathogenic microorganisms. Proc Natl Acad Sci U S A. 1998; 95(6): 3140- 3145.

10. Curran B, Jonas D, Grundmann H, Pitt T, and Dowson CG. Development of a multilocus sequence typing scheme for the opportunistic pathogen Pseudomonas aeruginosa. J. Clin. Microbiol.2004; 42: 5644-5649. doi: 10.1128/JCM.42.12.56445649 .

11. Waters V, Zlosnik JF, Yau YC, Speert DP, Aaron $\mathrm{SD}$, Guttman DS. Comparison of three typing method for Pseudomonas aerugenosa isolates from patients with cystic fibrosis. Eur. J. Clin. Microbiol. Infect. Dis.2012; 31(12): 3341-3350.

12. Wendt $M$ and Joon-Heo G. Multilocus sequence typing analysis of Pseudomonas aeruginosa isolated from pet Chinese stripe-necked turtles (Ocadiasinensis). Lab. Anim. Res.2016; 32(4): 208-216.

13. Franklin R,Matthew A, Karen B, Michael N, George $\mathrm{M}$ and Dwight J. Performance standards for antimicrobialsusceptibility testing; twentyfirst information supplement.An informational supplement for global applicationdeveloped through 
the Clinical and Laboratory StandardsInstitute consensus process.2011; 31(1): 1-165.

14. CLSI. Clinical Laboratory Standards Institute. Method for Dilution Antimicrobial suseptability Tests for Bacteria that grow aerobically; approved standard $11^{\text {th }}$ ed. CLSI Document M07-A11, ASM Press. 2018: Wayne Pennsylvania.

15. Almeida C, Azevedo NF, Santos S, Keevil CW and Vieira MJ. Correction: Discriminating MultiSpecies Populations in Biofilms with Peptide Nucleic Acid Fluorescence In Situ Hybridization (PNA FISH). PLoS ONE.2013; 8(6): 101-371.

16. Tang J,Kang M, Chen H, Shi X, Zhou R, Chen J and $\mathrm{Du}$ Y. The Staphylococcal nucclease prevents biofilm formation in Staphylococcus aureus and other biofilm-forming bacteria.Sci. China. Life.2011; 54(9):863-9.

17. Jarlier V, Nicolas MH, Fournier G, Philippon A. Extended spectrum $\beta$-lactamases conferring transferable resistance to newer $\beta$-lactam agents in Enterobacteriaceae: hospital prevalence and susceptibility patterns. Rev Infect Dis.1988; Vol.10:867-78.

18. Al Salam AK. Detection of extended spectrum-beta lactamase enzymes producing E. coli that isolated from urine. Kufa Journal for Veterinary Medical Sciences.2012; 3(1).

19. Felicita N A. Presence of coliform producing extended spectrum beta lactamase in sachet-water manufactured and sold in Abakaliki, Ebonyi state, Nigeria. International Research Journal Microbiology.2010; 1(2): 32-36.

20. Hameed ZM. Detection of CTX-M-1 and CTX-M-3 genes in virulent, Multidrug resistant Pseudomonas aeruginosa isolates. Master thesis- College of Science, Diyala University. 2017; In Arabic.

21. KaurAandSinghS.PrevalenceofExtendedSpectrum Betalactamase (ESBL) and Metallobetalactamase (MBL) Producing Pseudomonas aeruginosa and Acinetobacter baumannii Isolated from Various Clinical Samples. Hindawi Journal of Pathogens.2018; Article ID 6845985, 7 pages https://doi.org/10.1155/2018/6845985.

22. Fattma AA, Abdulwahab Z, Asaad S, Muhammad S. Isolation and Identification of Multi Drug Resistant Pseudomonas Aeruginosa Causing Wound Infection in Erbil City. Int. J. of Research Studies in Science, Engineering and Technology.2017; 4(12): 30-36.

23. Hayford O.Isolation and characterizations of MultiDrug resistant Pseudomonasaerugenosa from clinical, environmental and poultry litter sources in Ashanti region of Ghana. Thesis of master of philosophy. Kwame Nkrumah University of Science and Technology, Kumasi- Ghana/Faculty of Pharmacy and Pharmaceutical Sciences, 2016.

24. Tiexeira LM and Merquior VLC.Molecular typing method for the genus Pseudomonas. In: Molecular Typing in Bacterial Infections. New York: Springer Science and Business Media.2013: 421-426. 